\title{
Influence of Rhenium on the Mechanical Behavior and Fracture Mechanism of a Fine-Grain Superalloy at Elevated Temperatures
}

\author{
Jian-Hong Liao ${ }^{1, *}$, Hui-Yun Bor ${ }^{2}$, Chuen-Guang Chao ${ }^{1}$ and Tzeng-Feng Liu ${ }^{1}$ \\ ${ }^{1}$ Department of Materials Science and Engineering, National Chiao-Tung University, \\ 1001 Ta-Hsueh Road, Hsin-Chu 30049, Taiwan, R. O. China \\ ${ }^{2}$ Materials and Electro-Optics Research Division, Chung-Shan Institute of Science and Technology, \\ Lung-Tan, Tao-Yuan, 32599, Taiwan, R. O. China
}

This study investigated the influence of rhenium on the mechanical behavior and fracture mechanism of a fine-grain Mar-M247 superalloy at elevated temperatures. Tensile test results showed that the addition of 3 mass $\%$ Re significantly improved the ultimate tensile strength and yield strength from room temperature to $760^{\circ} \mathrm{C}$. Creep test results showed that steady-state creep behavior dominated creep properties under the test condition of $760^{\circ} \mathrm{C} / 724 \mathrm{MPa}$. The steady-state creep rate and creep life of alloy with 3 mass $\%$ Re was reduced by $31 \%$ and prolonged by $63 \%$, respectively, compared to alloy without Re. The improvement in tensile and creep properties in 3 mass $\%$ Re alloy was associated with a decrease in grain and $\gamma^{\prime}$ size and an increase in strength of $\gamma / \gamma^{\prime}$ matrix. However, adding 4.5 mass $\%$ Re resulted in a decrease in the tensile and creep properties due to the formation of needle-like $\mathrm{P}$ phase in the grain interior. Fracture analysis demonstrated that during tensile and creep tests, cracks initiated and propagated along grain boundary in alloy without Re and containing 3 mass \% Re alloy; however, in the alloy containing 4.5 mass $\%$ Re, cracks initiated and propagated along grain boundary and the P phase/matrix interface. Under the current tensile and creep conditions, 3 mass \% Re was an optimal addition for casting a fine-grain Mar-M247 superalloy. [doi:10.2320/matertrans.M2010299]

(Received September 6, 2010; Accepted November 8, 2010; Published January 25, 2011)

Keywords: superalloy, rhenium, tensile, creep, fracture

\section{Introduction}

Developed by the Martin-Marietta Company in the 1970s, Mar-M247 is a typical polycrystalline nickel-based superalloy which is strengthened by $\gamma^{\prime}$ phase precipitated in $\gamma$ matrix. ${ }^{1-3)}$ Its optimal alloy design and microstructural control give Mar-M247 high strength for applications at elevated temperatures up to $1034^{\circ} \mathrm{C}$. $^{3)}$ This alloy has been widely employed in fabricating advanced turbine blades and rotating parts in the aerospace industry because of its excellent castability and high temperature properties. ${ }^{1-4)}$ Basically, Mar-M247 consists of about $60 \%$ volume fraction of the $\gamma^{\prime}$ phase in the $\gamma$ matrix, which is a solid solution strengthened by cobalt, molybdenum, tungsten and chromium. ${ }^{1-4)}$ Carbon is employed to enhance the grain boundary (GB) strength in this conventional polycrystalline superalloy. ${ }^{1-4)}$ Because the fine-grain microstructure has advantages such as refined grains, carbides and precipitates, the fine-grain process was developed to improve the strength, creep and fatigue life of disc rotors, turbine blades and integral wheels working at intermediate temperature $\left(427 \sim 760^{\circ} \mathrm{C}\right) .{ }^{5-7)}$

The strength of Ni-base superalloys is mainly determined by precipitates of the ordered intermetallic $\mathrm{Ni}_{3}(\mathrm{Al}, \mathrm{Ti})$-type $\gamma^{\prime}$ phase in the face-centered cubic (FCC) $\gamma$ matrix. ${ }^{8}$ In modern Ni-base superalloys, the $\gamma^{\prime}$ phase is limited to a 65 $70 \%$ volume fraction for maximum hardening of precipitation. ${ }^{9,10)}$ Further improvement in the strength can be achieved through solid solution hardening of the $\gamma$ matrix, e.g., by adding refractory elements, such as Re, W, and Ta. ${ }^{9)}$ The main advance in this field was the introduction of $\mathrm{Re}$ as a new alloying element, leading to the development of so

*Graduate Student, National Chiao-Tung University called second generation ( 3 mass $\%$ Re) and third generation (6 mass\% Re) single crystal superalloys. ${ }^{11,12)}$ Single crystal superalloys offer improved tensile and creep properties at high temperature (above $950^{\circ} \mathrm{C}$ ). ${ }^{10-13)} \mathrm{Re}$ is known to have beneficial effects in preventing $\gamma^{\prime}$ coarsening during thermal exposure. It also strengthens the $\gamma$ matrix with a solid solution. ${ }^{12-18)}$ However, if the $\mathrm{Re}$ content is excessive, it tends to promote microstructural instability and from deleterious topological closed-packed (TCP) phases during exposure to elevated temperatures. ${ }^{19,20)}$ The crystal structures of the various TCP phases are very different. For instance, the $\mu$ and $\mathrm{R}$ phases are rhombohedral, the $P$ phase is orthorhombic, and the $\sigma$ phase is tetragonal. ${ }^{17)} \mathrm{A}$ number of observations show that the brittle TCP phase could initiate and propagate cracks, significantly decreasing the tensile, creep, and ductility properties. ${ }^{21,22)}$ Therefore, during superalloy design, addition of Re must be controlled, to prevent formation of TCP phase. Most studies to date have focused on behavior of single crystal superalloys containing $\mathrm{Re}$ at high temperature. There appears to be a lack of research examining the influence of adding Re to fine-grain Ni-base superalloys, or its intermediate temperature performance.

This study investigates Mar-M247 superalloys with 0, 3, and 4.5 mass\% additions of Re, focusing on the mechanical behavior and fracture mechanism of alloy at elevated temperatures. This study determined the maximum allowable addition of Re to the Mar-M247 superalloy, to promote the tensile and creep properties.

\section{Experimental}

In this study, 0, 3, and 4.5 mass $\%$ Re elements were added to Mar-M247 superalloy; the resulting alloys are referred to as Mar-M247, alloy A(3Re), and alloy B(4.5Re). The Mar- 
M247 superalloy and the added Re were melted in a vacuum furnace and poured into an investment mold to obtain cast rods using the Microcast- $X$ technique. Microcast- $X$, developed by Howmet Corporation, is a fine-grain technique with controlled low superheat and a high heat extraction rate. $3,6,7,23)$ The pour and mold temperatures were 1380 and $1100^{\circ} \mathrm{C}$, respectively. The compositions of the parent alloys used in this investigation are given in Table 1 . The chemistry of each alloy was determined using X-ray fluorescence (XRF), except for the Re content, which was determined by inductive coupled plasma (ICP) chemical analysis. Hotisostatic pressing (HIP) was utilized in this study to avoid casting pores that would affect the results of tensile and creep tests. HIP was executed at $1185^{\circ} \mathrm{C}$ under gaseous $\mathrm{Ar}$ at a pressure of $172.4 \mathrm{MPa}$ for $4 \mathrm{~h}$, followed by cooling in argon gas. Heat treatment of the solid solution was conducted at $1185^{\circ} \mathrm{C}$ for $2 \mathrm{~h}$ in vacuum, followed by cooling in argon gas. Samples were subjected to aging heat treatment at $871^{\circ} \mathrm{C}$ for $20 \mathrm{~h}$ in a vacuum and then cooled to room temperature (RT) in the furnace.

Grain size was measured by determining the mean linear intercept of the grains with optical microscopy (OM). Scanning electron microscopy (SEM) was adopted to characterize the microstructures. Transmission electron microscopy (TEM) was used to determine the crystal structure of the TCP phase. Energy dispersive spectroscopy (EDS) was used to determine the composition of precipitates. The aged specimens were subjected to Micro Vickers hardness

Table 1 The chemical compositions of superalloys investigated (mass\%).

\begin{tabular}{cccc}
\hline Alloy & Mar-M247 & A(3Re) & B(4.5Re $)$ \\
\hline Re & 0 & 2.92 & 4.42 \\
$\mathrm{Cr}$ & 8.35 & 8.42 & 8.40 \\
$\mathrm{Co}$ & 10.10 & 9.99 & 10.00 \\
$\mathrm{Mo}$ & 0.69 & 0.69 & 0.70 \\
$\mathrm{~W}$ & 9.91 & 10.02 & 10.03 \\
$\mathrm{Ta}$ & 3.05 & 3.01 & 2.99 \\
$\mathrm{Al}$ & 5.42 & 5.33 & 5.37 \\
$\mathrm{Ti}$ & 1.0 & 0.98 & 0.97 \\
$\mathrm{Hf}$ & 1.32 & 1.29 & 1.22 \\
$\mathrm{C}$ & 0.15 & 0.14 & 0.14 \\
$\mathrm{~B}$ & 0.02 & 0.02 & 0.02 \\
$\mathrm{Zr}$ & 0.04 & 0.04 & 0.04 \\
$\mathrm{Ni}$ & bal. & bal. & bal. \\
\hline
\end{tabular}

testing at RT. The Vickers hardness (Hv) was measured in the $\gamma / \gamma^{\prime}$ matrix of the grain interiors using a $100 \mathrm{~g}$ load. Tensile tests were performed using an Instron 1125 universal test machine with $0.2 \mathrm{~mm} / \mathrm{min}$. crosshead speed at RT, 427, and $760^{\circ} \mathrm{C}$ in atmosphere. Constant load creep tests were performed at $760^{\circ} \mathrm{C} / 724 \mathrm{MPa}$ in air using SATEC M3 creep testers. Test bars with a gauge diameter $6.3 \mathrm{~mm}$ and gauge length $26 \mathrm{~mm}$ were machined from cast rods in the heattreated condition. For each test condition at least four tests were conducted for tensile and creep tests. The fractograph was examined by SEM from the fracture surface and in longitudinal section.

\section{Results}

\subsection{Microstructure}

Figure 1 shows the grain size of three superalloys after heat treatment. The grain sizes of Mar-M247, alloy A(3Re), and $\mathrm{B}(4.5 \mathrm{Re})$ were 90,60 , and $50 \mu \mathrm{m}$, respectively. Figure 2 shows the microstructure of three superalloys. Basically, the microstructure of Mar-M247 was similar to that of alloy $\mathrm{A}(3 \mathrm{Re})$. The microstructures of the Mar-M247 and alloy $\mathrm{A}(3 \mathrm{Re})$ indicated that the main phases comprised: (1) the $\gamma$ matrix; (2) the reinforced phase $\gamma^{\prime}$; (3) strip-like and blocky carbides within the grain interior; (4) particle carbides at the GB; and (5) rosette eutectic structure of $\gamma-\gamma^{\prime}$ (Fig. 2(a),(b)). The Mar-M247 showed a typical aged treatment microstructure, which consisted of $\gamma^{\prime}$ particles $0.8 \sim \mu \mathrm{m}$ in size homogeneously distributed throughout the bulk samples. Alloy B(4.5Re) exhibited the non-homogeneously distributed $\gamma^{\prime}$ phase; the fine $\gamma^{\prime}$ particles existed in the core of the grain, however, the larger, block shaped $\gamma^{\prime}$ particles $(1 \sim 4 \mu \mathrm{m}$ in size) were situated in the region near partial GB (Fig. 2(c)). In addition, the needle-like TCP phase was observed within the grain interior in the alloy $\mathrm{B}(4.5 \mathrm{Re})$, and EDS measurements (Fig. 2(d)) indicated that this phase had a high content of Re and W. TEM identified the TCP phase as the orthorhombic $\mathrm{P}$ phase (Fig. 3). Figure 4 shows the highly magnified SEM morphology of $\gamma^{\prime}$ precipitates in the grain core. The block $\gamma^{\prime}$ phases were distributed in the matrix of the Mar-M247. Block $\gamma^{\prime}$ and fine cube $\gamma^{\prime}$ were observed in alloy $\mathrm{A}(3 \mathrm{Re})$; alloy $\mathrm{B}(4.5 \mathrm{Re})$ contained the fine cube $\gamma^{\prime}$. The size of block $\gamma^{\prime}$ and fine cube $\gamma^{\prime}$ were about 0.8 and $0.3 \mu \mathrm{m}$, respectively. Finally, it is emphasized that no casting pores were observed in any of the alloys, ensuring that the tensile and creep test results were not affected by casting pores.
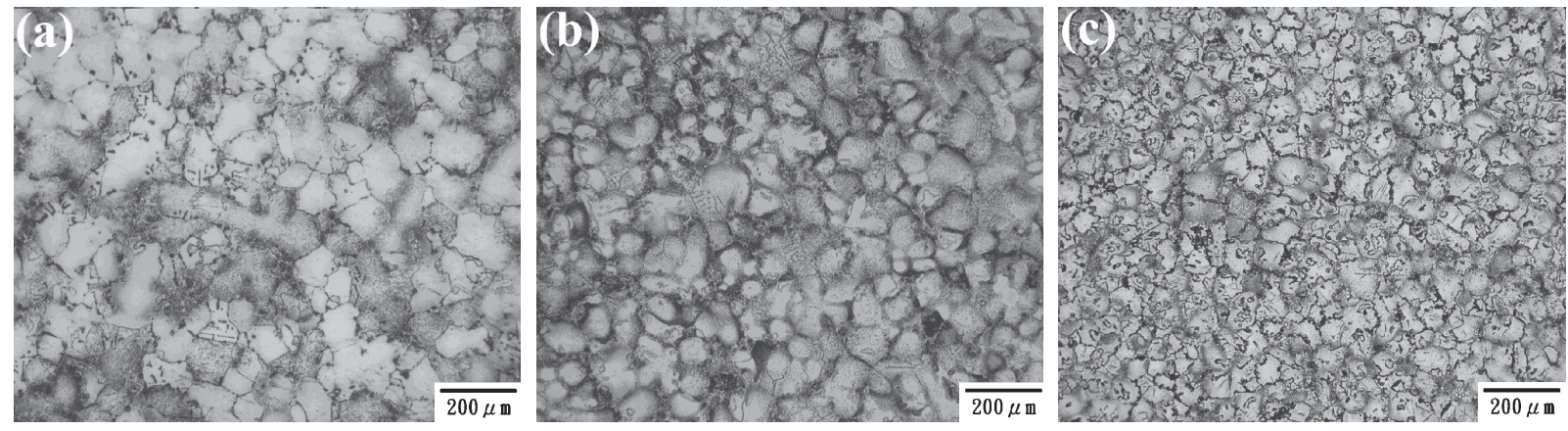

Fig. 1 OM of (a) Mar-M247, (b) alloy A(3Re), and (c) alloy B(4.5Re) after heat treatment. 

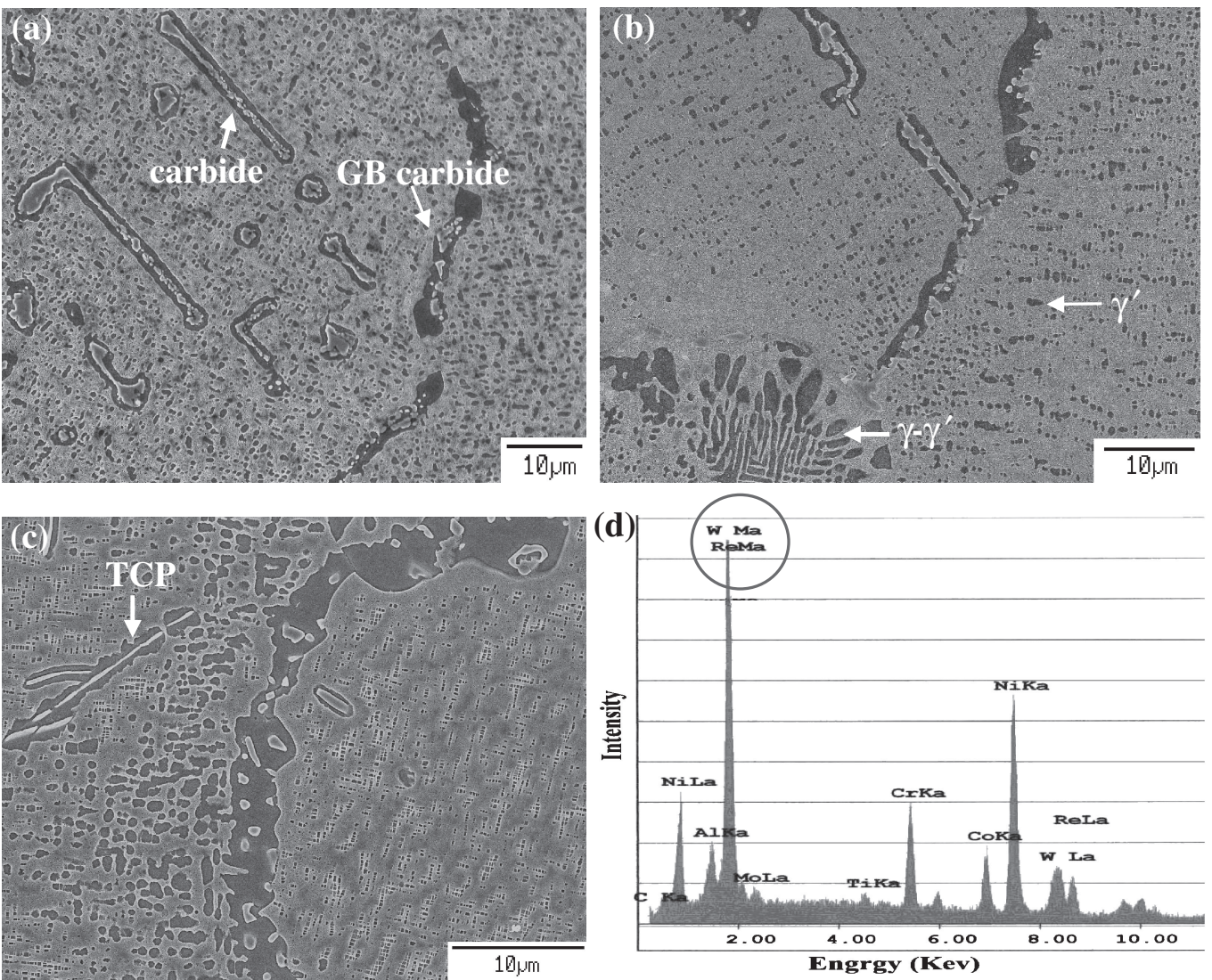

Fig. 2 SEM microstructure of (a) Mar-M247, (b) alloy A(3Re), and (c) alloy B(4.5Re) after heat treatment. (d) The EDS spectra of TCP phase in alloy $\mathrm{B}(4.5 \mathrm{Re})$.
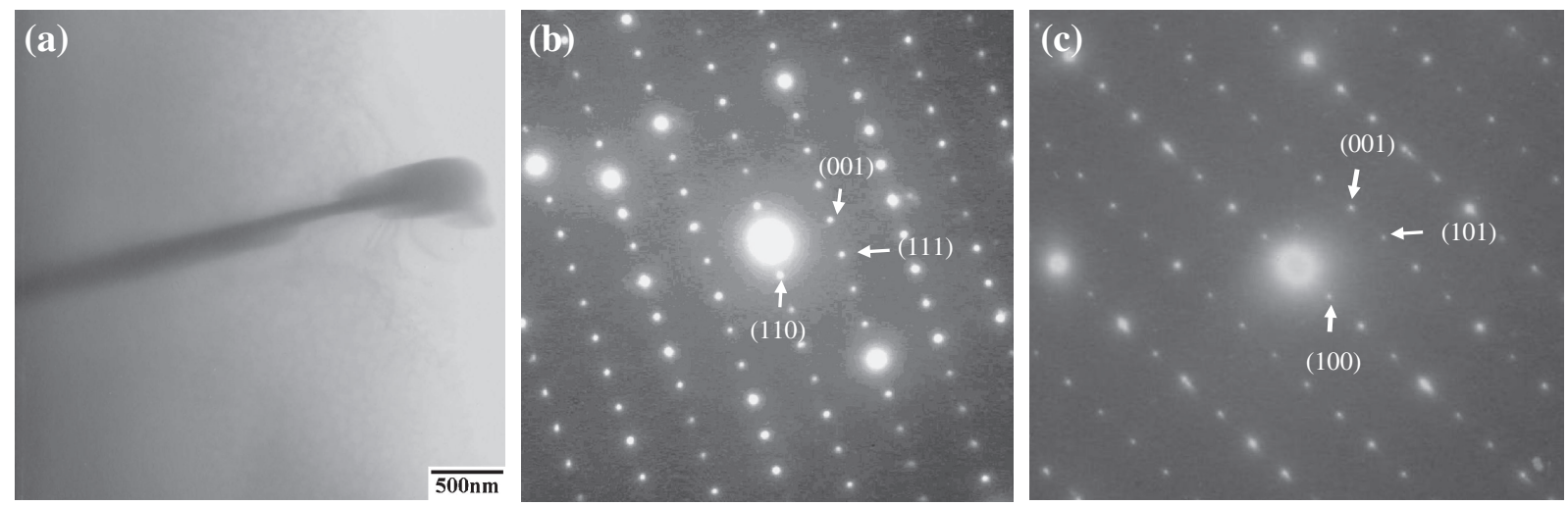

Fig. 3 The TEM (a) bright-field image of the P phase, (b) selected-area diffraction pattern (SADP) with [110] zone, and (c) SADP with [010] zone.
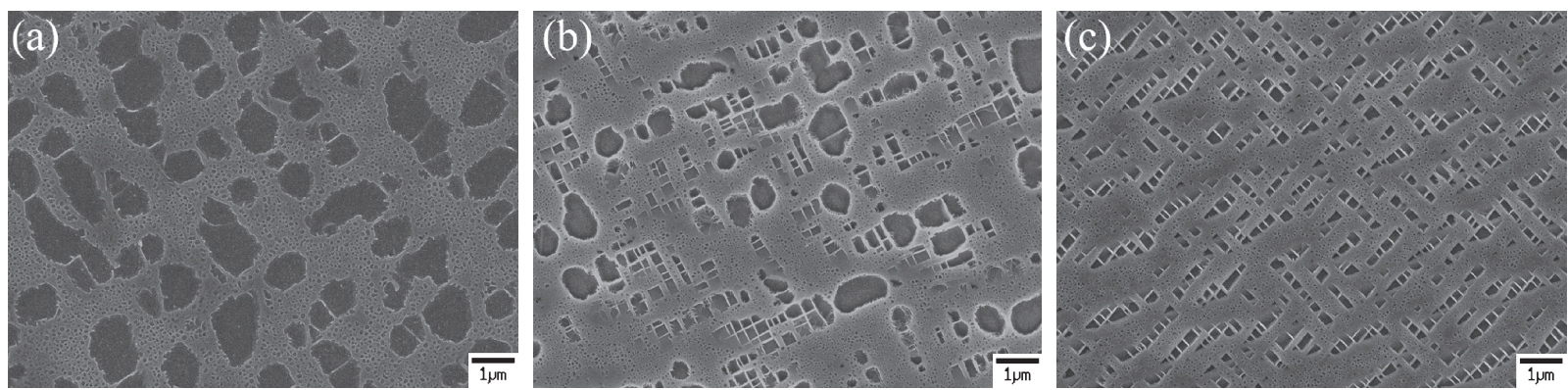

Fig. 4 The $\gamma^{\prime}$ phase morphology in grain core after heat treatment. (a) Mar-M247, (b) alloy A(3Re), and (c) alloy B(4.5Re). 


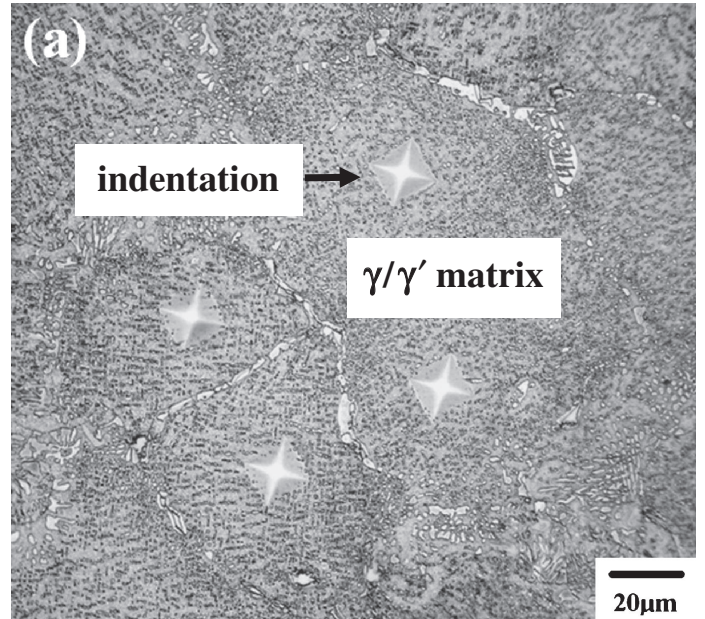

(b)

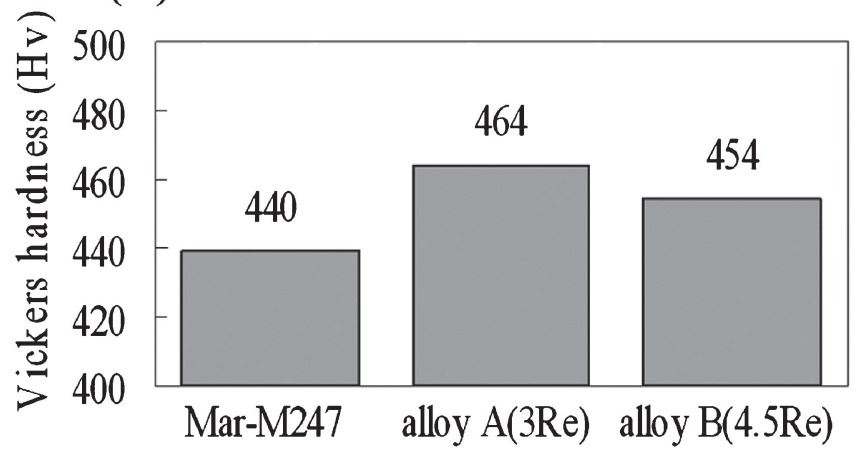

Fig. 5 (a) OM image of Mar-M247 with micro-indentations in the $\gamma / \gamma^{\prime}$ matrix and (b) Micro Vickers hardness.

\subsection{Microhardness and tensile tests}

Figure 5(a) shows a typical OM image of Mar-M247 with micro-indentations in the $\gamma / \gamma^{\prime}$ matrix. To investigate the influence of Re addition to the $\gamma / \gamma^{\prime}$ matrix, the indentations were made in the $\gamma / \gamma^{\prime}$ matrix, where no carbide, $\gamma-\gamma^{\prime}$ eutectic phase, and TCP phase exist. Microhardness values of various Re containing alloys are shown in Fig. 5(b). The hardness values are averaged for over 20 indents. The average $\mathrm{Hv}$ of Mar-M247, alloy A(3Re), and alloy B(4.5Re) was 440, 464, and 454 , respectively. The results showed that the alloy $\mathrm{A}(3 \mathrm{Re})$ had the $\gamma / \gamma^{\prime}$ matrix with the highest degree of hardness.

The tensile properties of Mar-M247 superalloy with various $\mathrm{Re}$ contents, tested at room and elevated temperatures, are shown in Fig. 6. In the results for RT tests, the average ultimate tensile strength (UTS), $0.2 \%$ offset yield strength (YS), and elongation (EL) of Mar-M247 were $1131 \mathrm{MPa}, 977 \mathrm{MPa}$, and 5.4\%, respectively. Alloy A(3Re) exhibited the highest UTS and YS, which were 1203 and $1062 \mathrm{MPa}$, respectively. The UTS and YS of alloy A(3Re) were promoted by 6.4 and $8.7 \%$, respectively, as compared to Mar-M247. On the other hand, the EL was quite similar to that of Mar-M247. Conversely, the UTS, YS, and EL of alloy $\mathrm{B}(4.5 \mathrm{Re})$ had decreased to $1095 \mathrm{MPa}, 944 \mathrm{MPa}$, and $2.2 \%$, respectively. In the results at elevated temperatures, the tensile properties exhibited a similar tendency to those at RT. Alloy $\mathrm{A}(3 \mathrm{Re})$ exhibited the best UTS and YS, and an EL
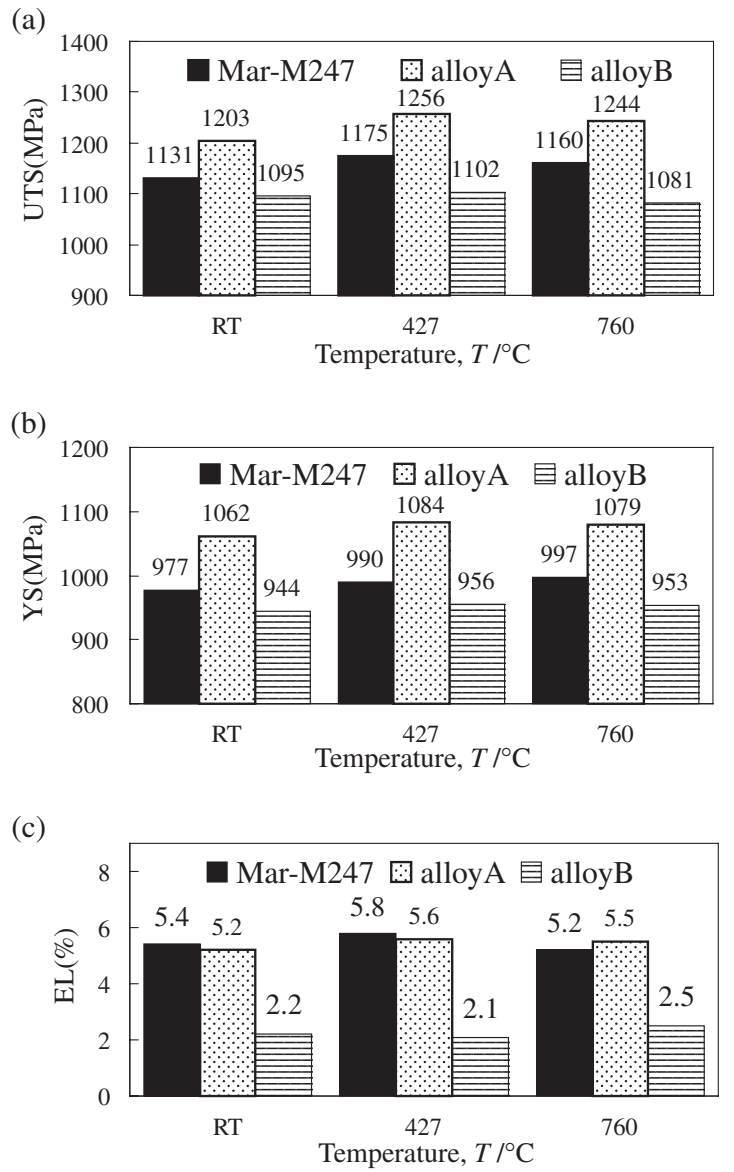

Fig. 6 The tensile properties of Mar-M247 superalloy with various Re contents tested at various temperatures. (a) UTS, (b) $0.2 \%$ offset YS, and (c) EL (average value).

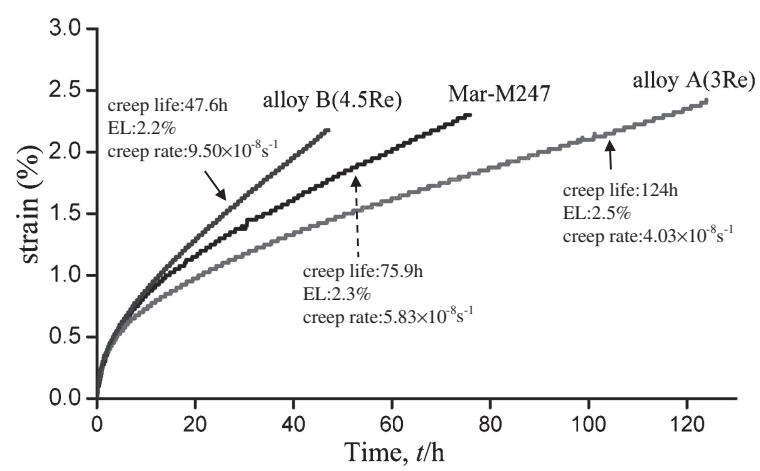

Fig. 7 Creep curves of Mar-M247 superalloy with various Re contents tested under $760^{\circ} \mathrm{C} / 724 \mathrm{MPa}$.

similar to that of Mar-M247, and the alloy B(4.5Re) displayed the lowest tensile properties.

\subsection{Creep tests}

Figure 7 illustrates the typical creep strain curves of Mar-M247 superalloy with various $\mathrm{Re}$ contents at $760^{\circ} \mathrm{C} /$ $724 \mathrm{MPa}$ condition. The creep curves of various Re-containing alloys show the same tendency, with a short primary stage of creep followed by a steady-state stage leading to failure, without entering the accelerating stage. For all of the alloys, 
Table 2 Creep test results of Mar-M247 superalloy with various Re contents under $760^{\circ} \mathrm{C} / 724 \mathrm{MPa}$.

\begin{tabular}{|c|c|c|c|c|c|c|}
\hline & $\begin{array}{c}\text { Creep life } \\
\text { (h) }\end{array}$ & $\begin{array}{l}\mathrm{EL} \\
(\%)\end{array}$ & $\begin{array}{l}\text { *Time to } 1 \% \\
\text { creep } \\
\text { (h) }\end{array}$ & $\begin{array}{l}\text { *Time to } 2 \% \\
\text { creep } \\
\text { (h) }\end{array}$ & $\begin{array}{l}\text { * Steady-state } \\
\text { creep rate } \\
\left(\mathrm{s}^{-1}\right)\end{array}$ & $\begin{array}{c}\text { *Period of steady-state } \\
\text { creep } \\
\text { (h) }\end{array}$ \\
\hline EMS-55447 & $>23$ & $>2$ & - & - & - & - \\
\hline Mar-M247 & $65 \sim 75.9$ & $2.1 \sim 2.3$ & 14.0 & 58.8 & $5.83 \times 10^{-8}$ & 61.9 \\
\hline $\mathrm{A}(3 \mathrm{Re})$ & $108 \sim 124.0$ & $2.1 \sim 2.5$ & 20.6 & 89.7 & $4.03 \times 10^{-8}$ & 103.4 \\
\hline $\mathrm{B}(4.5 \mathrm{Re})$ & $33 \sim 47.6$ & $2.0 \sim 2.2$ & 12.5 & 41.1 & $9.59 \times 10^{-8}$ & 35.1 \\
\hline
\end{tabular}

*obtain from creep curves of Fig. 7.
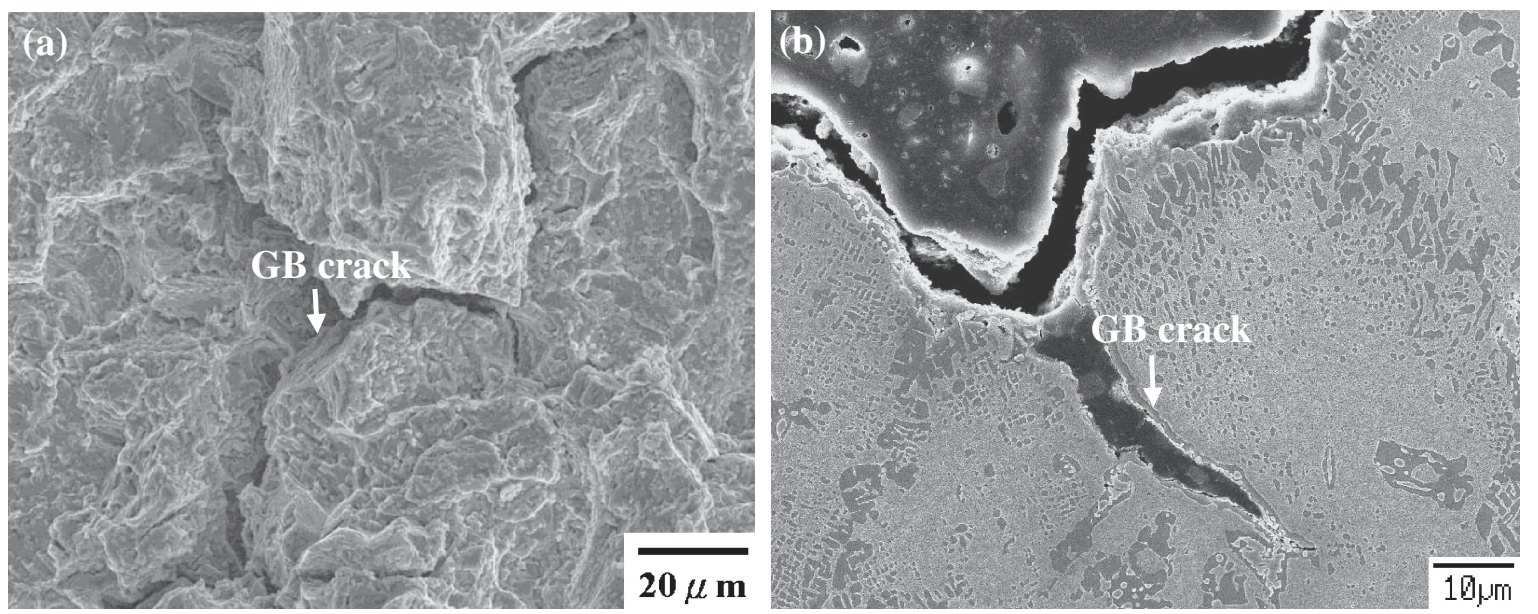

Fig. 8 Fractographs of the alloy A(3Re) after RT tensile test. (a) fracture surface and (b) longitudinal section.

the steady-state creep initiated at nearly the same strain (1\%). It is obvious that the steady-state creep behavior dominated the creep properties. The creep data are listed in Table 2. According to Engine Material Specification EMS-55447, ${ }^{24)}$ the creep life of the Mar-M247 superalloy must be longer than $23 \mathrm{~h}$ and the EL must exceed $2 \%$ at $760^{\circ} \mathrm{C} / 724 \mathrm{MPa}$. During service, turbine blades are usually strained below 1 or $2 \%$, therefore the criterion of time to reach $1 \%\left(t_{1 \%}\right)$ or $2 \%$ strain $\left(t_{2} \%\right)$ was chosen as a main indication for creep strength. ${ }^{3,14)}$ For the Mar-M247, alloy A(3Re), and alloy $\mathrm{B}(4.5 \mathrm{Re})$, the creep life and EL are all exceeded specifications. It is obvious that the alloy $\mathrm{A}(3 \mathrm{Re})$ has the longest $t_{1 \%}$, $t_{2} \%$, and creep life, of $20.6,89.7$, and $124 \mathrm{~h}$, respectively. In other words, the $t_{1 \%}, t_{2} \%$, and creep life of alloy A(3Re) were improved by $\sim 47, \sim 53$, and $\sim 63 \%$, respectively, compared to Mar-M247. Furthermore, compared with Mar-M247, the period of steady-state creep and the creep rate were effectively prolonged by $\sim 67 \%$ and decreased by $\sim 31 \%$, respectively. Alloy $\mathrm{B}(4.5 \mathrm{Re})$ exhibited the highest steadystate creep rate, and the shortest period of steady-state creep and creep life.

\subsection{Fractographic observation}

To investigate the effect of $\mathrm{Re}$ addition on fracture behavior in tensile and creep tests, both the fracture surface and longitudinal section adjacent to the fracture region were examined. Observation from the fracture surface of a RT tensile tested specimen of alloy A(3Re) (Fig. 8(a)), shows that the crack occurred mainly along the GB. Figure $8(\mathrm{~b})$ shows identical evidence to that in Fig. 8(a): a continuous carbide particle film is clearly seen at the crack position of the GB, indicating a typical intergranular fracture. A similar fracture was shown in Mar-M247-a crack was observed along the GB. For the alloy $\mathrm{B}(4.5 \mathrm{Re})$ sample, however, the fractography results were quite different. Observation of the fracture surface of alloy $\mathrm{B}(4.5 \mathrm{Re})$ showed the crack on the GB, and a secondary crack was observed within the grain interior (Fig. 9(a)). In the longitudinal section, a crack was observed on the GB, and needle-like TCP phases existed in the grain interior (Fig. 9(b)), very similar in size to the length of the secondary crack observed in Fig. 9(a). No other phases in the microstructure had similar dimensions. As shown in Fig. 9(c), the microcracks were visible in the high magnification SEM fractography. Obviously, rupture occurred because the cracks initiated and propagated along the TCP/matrix interface or at the TCP Phase. The TCP phase was identified as $\mathrm{W}$ and Re-rich $\mathrm{P}$ phase by SEM/EDS (Fig. 9(d)). In elevated temperature tensile tests, each alloy had the same fracture mode as in the RT tests.

In the $760^{\circ} \mathrm{C} / 724 \mathrm{MPa}$ creep tests, the fracture surface of alloy $\mathrm{A}(3 \mathrm{Re})$ showed that cracks occurs mainly along the GB (Fig. 10(a)). Figure 10(b) showed identical cracking along the GB, indicating a typical intergranular fracture. A similar fracture mode was shown in the Mar-M247. For the fracture surface of alloy $\mathrm{B}(4.5 \mathrm{Re})$, the cracks were observed on the GB, and secondary cracks were observed within the grain interior (Fig. 11(a)). Similarly, in Fig. 11(b), the cracks were observed on the GB and along the $\mathrm{TCP} /$ matrix interfaces. The dimensions of needle-like 

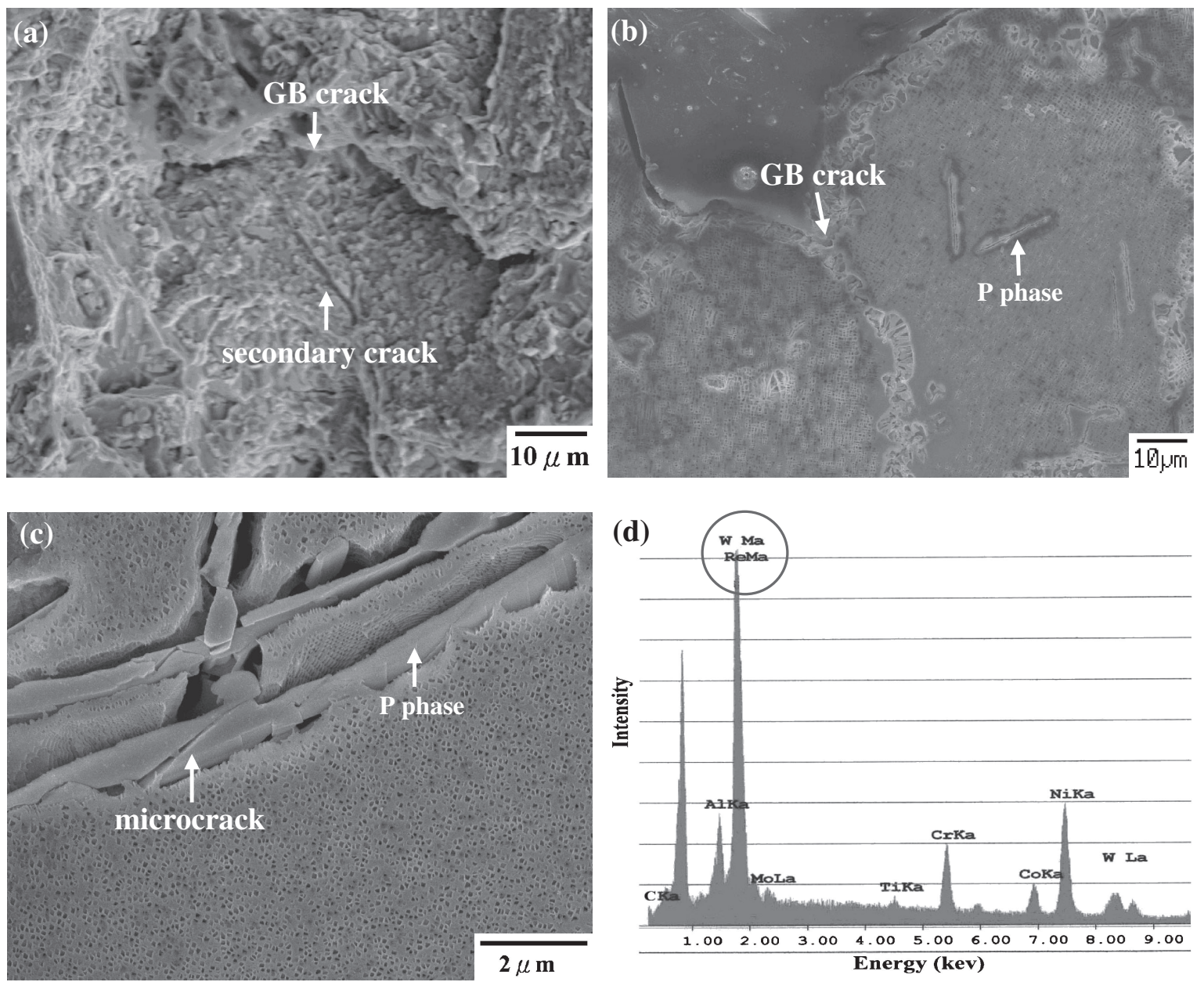

Fig. 9 Fractographs of the alloy B(4.5Re) after RT tensile test. (a) fracture surface, (b) longitudinal section (crack occurs at GBs), (c) longitudinal section (microcrack occurs at $\mathrm{P}$ phase and $\mathrm{P} /$ matrix interface), and (d) EDS spectra at $\mathrm{P}$ phase.
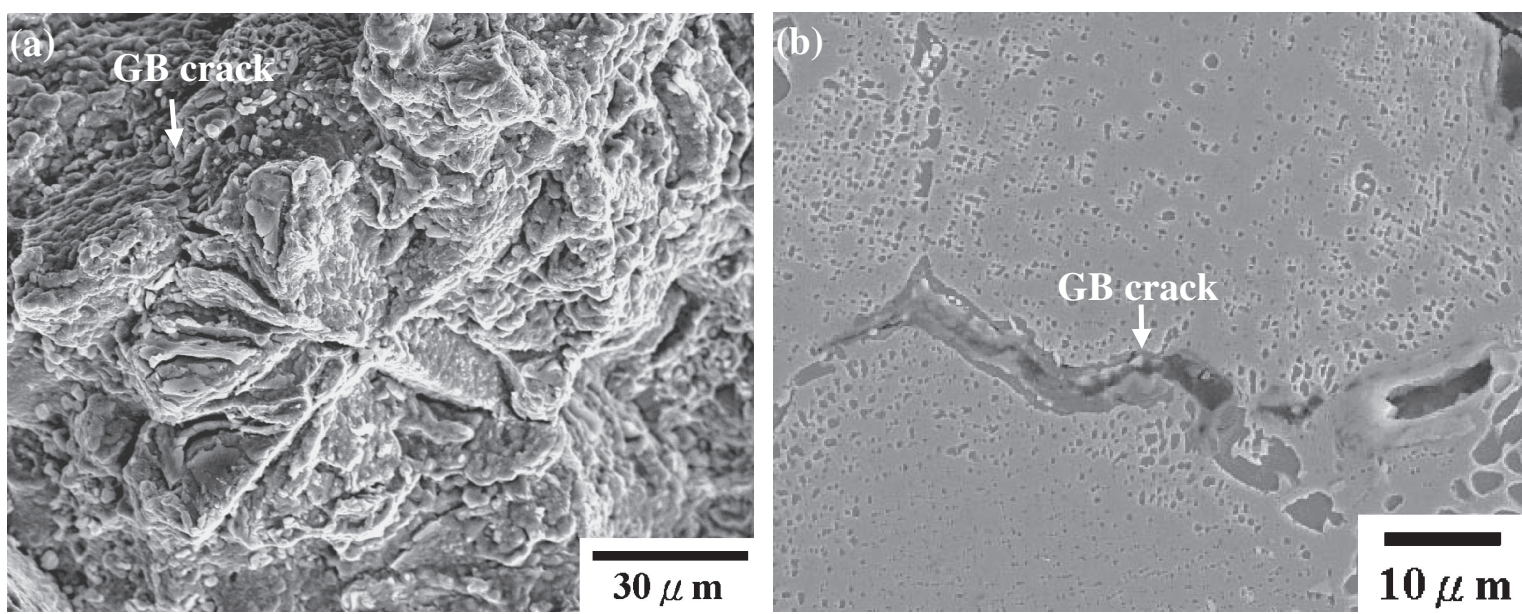

Fig. 10 Fractographs of the alloy $\mathrm{A}(3 \mathrm{Re})$ after creep test under $760^{\circ} \mathrm{C} / 724 \mathrm{MPa}$. (a) fracture surface and (b) longitudinal section.

TCP phase were similar to those of the secondary crack observed in Fig. 11(a). The microcracks were observed at the needle-like TCP phase (Fig. 11(c)), and the TCP phase was identified as $\mathrm{W}$ and Re-rich $\mathrm{P}$ phase by SEM/EDS (Fig. 11(d)). Finally, no evidence showed that that directional coarsening of $\gamma^{\prime}$, which is called rafting, took place during the creep test in any of the alloys.

\section{Discussion}

\subsection{Effect of $\operatorname{Re}$ on the microhardness and tensile properties}

The microhardness test performed in the grain interiors indicated the strength of $\gamma / \gamma^{\prime}$ matrix. Although microhardness test verified that Re addition change the strength of $\gamma / \gamma^{\prime}$ 

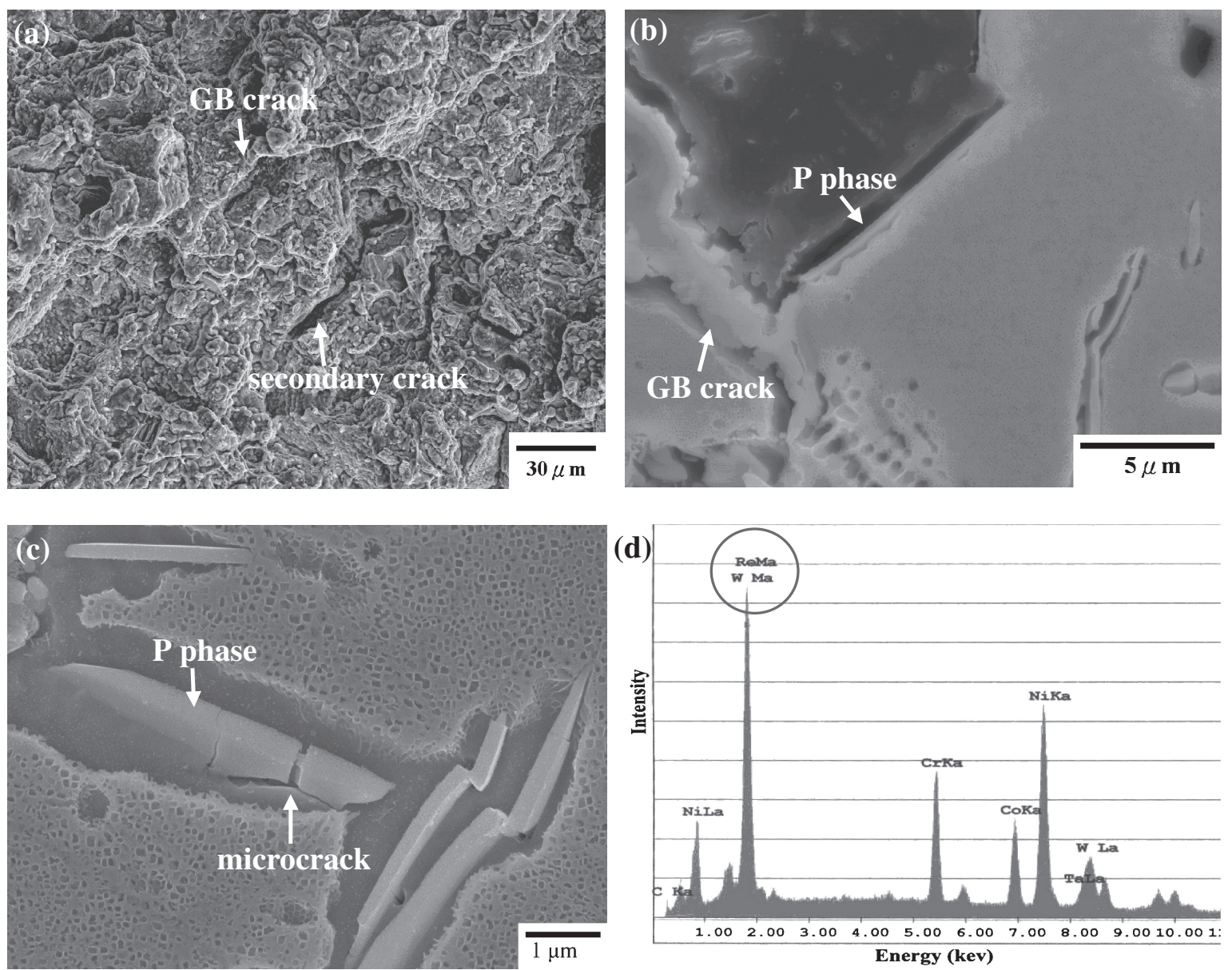

Fig. 11 Fractographs of the alloy $\mathrm{B}\left(4.5 \mathrm{Re}\right.$ ) after creep test under $760^{\circ} \mathrm{C} / 724 \mathrm{MPa}$. (a) fracture surface, (b) longitudinal section, (c) longitudinal section (microcrack occurs at $\mathrm{P}$ phase and $\mathrm{P} /$ matrix interface), and (d) EDS spectra at $\mathrm{P}$ phase.

matrix, it is hard to estimate the difference of the $\gamma / \gamma^{\prime}$ matrix strength is affected by $\gamma^{\prime}$ precipitate or $\gamma$ matrix. Most studies reported that the large atomic radius of Re mainly partitioned to the $\gamma$ matrix increase the $\gamma / \gamma^{\prime}$ lattice misfit, and a large lattice misfit produced large random stresses in the $\gamma$ matrix, improving the strength of $\gamma$ matrix. ${ }^{10,11)}$ Moreover, Mott concluded that solid solution hardening could be accounted for by internal strain generated by inserting solute atoms into an elastic matrix. ${ }^{25)}$ Therefore, the improvement of the $\gamma / \gamma^{\prime}$ matrix strength in the grain interior probably attributes to $\mathrm{Re}$ solute strengthening of the $\gamma$ matrix. The microhardness test results showed that adding 3 mass $\%$ Re could maximize the strength of $\gamma / \gamma^{\prime}$ matrix, and then decrease with an addition of 4.5 mass $\% \operatorname{Re}$ addition. The drop in strength of the $\gamma / \gamma^{\prime}$ matrix in alloy $\mathrm{B}(4.5 \mathrm{Re})$, which was caused by formation of the TCP phase, resulted from a depletion in the surrounding $\gamma$ matrix of $\mathrm{Re}$ and $\mathrm{W}$ that were solid solution strengthening elements.

Tensile tests showed that alloy $\mathrm{A}(3 \mathrm{Re})$ exhibited the highest UTS and YS. In comparison with Mar-M247, alloy $\mathrm{A}(3 \mathrm{Re})$ increased the UTS to $6.4,6.9$, and $7.2 \%$, and YS to $8.7,9.5$, and $8.2 \%$ at $\mathrm{RT}, 427$, and $760^{\circ} \mathrm{C}$, respectively. Conversely, alloy $\mathrm{B}(4.5 \mathrm{Re})$ decreased both UTS and YS. On the other hand, the EL was nearly constant $(5.2 \sim 5.8 \%)$ in Mar-M247 and alloy $\mathrm{A}(3 \mathrm{Re})$ at various temperatures. It is obvious that adding 3 mass $\%$ Re could not affect the ductility, compared to an alloy without Re. However, the EL decreased when the Re level was increased to 4.5 mass\% at room and elevated temperatures. The effects on the grain size, $\gamma / \gamma^{\prime}$ matrix strength, and TCP phase on tensile properties are discussed as follow.

Generally, the strength of an alloy strongly depends on grain size. According to the Hall-Petch equation, strength is a function of the reciprocal of the square root of the grain size. $^{26)}$ It is well known that the GB acts as an obstacle to slip dislocations. Thus, the applied stress required to cause a slip to pass through the GB increases with a decrease in grain size. In theory, if grain size is considered the only influence on strength, alloy $\mathrm{B}(4.5 \mathrm{Re})$ should have the highest strength at RT and elevated temperatures. In fact, the alloy $\mathrm{A}(3 \mathrm{Re})$, rather than alloy $\mathrm{B}(4.5 \mathrm{Re})$, showed the highest UTS and YS. The microhardness testing showed that alloy $\mathrm{A}(3 \mathrm{Re})$ exhibited the highest strength of the $\gamma / \gamma^{\prime}$ matrix representing the highest ability to impede dislocation to move in $\gamma / \gamma^{\prime}$ matrix. Although, alloy $\mathrm{B}(4.5 \mathrm{Re})$ revealed the second highest $\gamma / \gamma^{\prime}$ strengthening in this study, it exhibited the worst tensile properties. There must be other factors causing the drop in strength of alloy $\mathrm{B}(4.5 \mathrm{Re})$. The presence of TCP phases was reported to result in significantly decreased ductility and strength in two ways: First, its brittle, needle-shaped morphology is ideal for crack initiation and propagation, leading to brittle failure; and the formation of TCP phases 
decreases the solution strengthening metal content in the $\gamma$ matrix. ${ }^{17,18,27)}$ Fractographic analysis verified that microcracks existed in the $\mathrm{P}$ phases, indicating that the needle-liked $\mathrm{P}$ phases were associated with a local stress concentration, which may potentially act as initiation sites for cracking. In addition, the $\mathrm{W}$ and Re-rich $\mathrm{P}$ phases decreased the strength of alloy, due to the removal of solid solution strengthening elements from the $\gamma$ matrix. While the crack initiated on the $\mathrm{P} /$ matrix interfaces, the $\gamma / \gamma^{\prime}$ matrix did not have enough strength to resist crack propagation. Thus, cracks propagate easily along the $\mathrm{P}$ phases under stress. As mentioned above, grain refinement and improvement in the strength of the $\gamma / \gamma^{\prime}$ matrix contributed to the improvement of UTS and YS of alloy $\mathrm{A}(3 \mathrm{Re})$. The formation of the needle-shaped $\mathrm{P}$ phase appeared to be a major contributing factor in the deterioration of the tensile properties in alloy $\mathrm{B}(4.5 \mathrm{Re})$.

\subsection{Effect of $\operatorname{Re}$ on the creep properties}

It has been reported that a greater curve in GB makes GB more difficult to slide. ${ }^{28)}$ In addition, the finer grain makes cracks along the GB that have longer cracking paths to crack, consequently, harder to rupture. Therefore, a finer grain size, with more curved GB, is beneficial for the creep life and EL. According to the creep deformation map of a Mar-M247 related superalloy (Mar-M200), the creep mechanism with $100 \mu \mathrm{m}$ grain size under the conditions of $760^{\circ} \mathrm{C} / 724 \mathrm{MPa}$ was controlled by dislocation glide ${ }^{29)}$ that is, the creep behavior was dominated by the interaction between dislocations and obstacles such as $\gamma^{\prime}$ precipitates. Moreover, the mobility of dislocations in $\gamma / \gamma^{\prime}$ matrix during the creep depends on the strength of the $\gamma$ matrix and is related to $\gamma^{\prime}$ strength, size, and spacing (the distance between the $\gamma^{\prime}$ precipitates). Firstly, the Re addition increases the strength of the $\gamma / \gamma^{\prime}$ matrix representing increase of the $\gamma$ or $\gamma^{\prime}$ strength to inhibit dislocation motion. Secondly, most studies show that a cuboidal $\gamma^{\prime}$ with a size of $\sim 0.1-0.5 \mu \mathrm{m}$ can efficiently impede dislocation motion, and consequently achieve the best creep strength. ${ }^{27,30)}$ In this study, the morphology of the $\gamma^{\prime}$ phase translated from a coarse block shape $(0.8 \mu \mathrm{m}$ in size $)$ to fine cuboidal shape $(0.3 \mu \mathrm{m}$ in size $)$ as $\operatorname{Re}$ content increased from 0 to 4.5 mass $\%$ is another factor to improve creep strength. Finally, Re addition can increase amounts of small particle of $\gamma^{\prime}$ exist in the $\gamma$ matrix, resulting in shorting of the $\gamma^{\prime}$ spacing to hinder the dislocation movement.

As mentioned above, the alloy $\mathrm{B}(4.5 \mathrm{Re})$ with the finest grain and $\gamma^{\prime}$ size should show the best creep properties, however creep life is substantially prolonged in alloy $\mathrm{A}(3 \mathrm{Re})$, rather than in alloy $\mathrm{B}(4.5 \mathrm{Re})$. Fractographic observations showed that the cracks of Mar-M247 and alloy A(3Re) were along the GB; however, the fractographic observations show that, for alloy $\mathrm{B}(4.5 \mathrm{Re})$, the cracks were along the GB as well as along the $\mathrm{P}$ phase/matrix interface-adding another source for carking. The needle-like TCP phase could act as a barrier for moving dislocations, leading to incoherence in the weak $\mathrm{P} /$ matrix interface, thereby causing interfacial cracks. ${ }^{27)}$ Moreover, formation of the $\mathrm{P}$ phase consumed the Re and W solid solution strengthening elements, resulting in a decreased resistance to dislocation moving in the $\gamma$ matrix. Thus, the $\mathrm{P}$ phase caused creep accelerate to failure, which could be verified by the highest steady-state creep rate in alloy $\mathrm{B}(4.5 \mathrm{Re})$. In addition, SEM observation of alloy $\mathrm{B}(4.5 \mathrm{Re})$ showed inhomogeneously distributed $\gamma^{\prime}$ phase, with the large $\gamma^{\prime}$ phases existing in the region near the GB. To authors' experiment, this coarse $\gamma^{\prime}$ phases appeared in as-cast state. Obviously, as Re additions are increased, complete homogenization of solidification becomes difficult. It also indicates that the solution heat treatment condition used in this study cannot solute the coarse $\gamma^{\prime}$ phases. The increase of the local $\gamma^{\prime}$ particle size is another factor damaging the creep strength. However, no crack occurred at the coarse $\gamma^{\prime}$ phases. Therefore, the formation of needle-like $\mathrm{P}$ phase seemed to play the major detrimentally affecting creep properties in alloy $\mathrm{B}(4.5 \mathrm{Re})$. In summary, a decrease in grain and $\gamma^{\prime}$ size and an increase in strength of the $\gamma / \gamma^{\prime}$ matrix contributed to the improvement in creep strength. Conversely, the formation of needle-like $\mathrm{P}$ phase is detrimental to the creep properties.

\section{Conclusions}

(1) Microhardness tests showed that addition of Re could promote the strength of the $\gamma / \gamma^{\prime}$ matrix. In particular, adding the 3 mass\% Re to Mar-M247 produced the strongest $\gamma / \gamma^{\prime}$ matrix.

(2) Grain refinement and improvement of the $\gamma / \gamma^{\prime}$ matrix strength contributed to the improvement of UTS and YS of alloy $\mathrm{A}(3 \mathrm{Re})$. The decrease in tensile properties of alloy $\mathrm{B}(4.5 \mathrm{Re})$ was caused by the formation of needlelike $\mathrm{P}$ phase.

(3) The $760^{\circ} \mathrm{C} / 724 \mathrm{MPa}$ creep tests showed that the steadystate creep behavior dominated creep properties. The steady-state creep rate and creep life of alloy $\mathrm{A}(3 \mathrm{Re})$ was reduced by $31 \%$ and prolonged by $63 \%$, respectively, compared to Mar-M247. The improvement in creep strength was associated with a decrease in grain and $\gamma^{\prime}$ size and an increase in strength of the $\gamma / \gamma^{\prime}$ matrix. The formation of needle-like $\mathrm{P}$ phase, which increases the creep rate, was the major detriment to the creep life of alloy $\mathrm{B}(4.5 \mathrm{Re})$.

(4) Cracks initiated and propagated along the GB in MarM247 and alloy $\mathrm{A}(3 \mathrm{Re})$ in the tensile and creep tests. For alloy $\mathrm{B}(4.5 \mathrm{Re})$, the cracks initiated and propagated along both the GB and needle-like $\mathrm{P}$ phase.

\section{Acknowledgments}

The authors would like to thank Mr. Y. P. Huang for his help in mechanical property evaluation. The equipment support of processing from Mr. G. D. Cai is also thankfully acknowledged.

\section{REFERENCES}

1) H. Y. Bor, C. G. Chao and C. Y. Ma: Metall. Trans. A 30A (1999) 551561.

2) H. Y. Bor, C. G. Chao and C. Y. Ma: Metall. Trans. A 31A (2000) 1365-1373.

3) W. F. Brown and S. J Setlak: Aerospace structural Metals Handbook, 39th, Vol. 6, (1999) Code 4218.

4) M. V. Nathal, R. D. Maier and L. J. Ebert: Metall. Trans. A 13A (1982) 1767-1774.

5) C. T. Sims, N. S. Stoloff and W. C. Hagel: Superalloys II, (John Wiley 
\& Sons, New York, 1987) pp. 420-426.

6) C. N. Wei, H. Y. Bor and L. Chang: Mater. Trans. 49 (2008) 193-201.

7) H. E. Huang and C. H. Koo: Mater. Trans. 45 (2004) 554-561.

8) C. T. Sims, N. S. Stoloff and W. C. Hagel: Superalloys II, (John Wiley \& Sons, New York, 1987) pp. 98-105.

9) J. Rüusing, N. Wanderka, U. Czubayko, V. Naundorf, D. Mukherji and J. Rösler: Scr. Meter. 46 (2002) 235-240.

10) F. Diologent and P. Caron: Mater. Sci. Eng. A 385 (2004) 245-257.

11) K. Durst and M. Göken: Mater. Sci. Eng. A 387-389 (2004) 312-316

12) G. E. Fuchs: Mater. Sci. Eng. A 300 (2001) 52-60.

13) M. V. Acharya and G. E. Fuchs: Mater. Sci. Eng. A 381 (2004) 143 153.

14) S. Wöllmer, T. Mack and U. Glatzel: Mater. Sci. Eng. A 319-321 (2001) 792-795.

15) A. F. Giamei and D. L. Anton: Metall. Trans. A 16A (1985) 19972005.

16) R. Burgel, J. Grossmann, O. Lusebrink, H. Mughrabi, F. Pyczak, R. F. Singer and A. Volek: Proc. 10th Int. Symp. on Superalloys, ed. by K. A Green, T. M. Pollock, H. Harada, T. E. Howson, R. C. Reed, J. J. Schirra and S. Walston, (TMS, Warrendale, PA, 2004) pp. 25-34.

17) C. M. F. Rae and R. C. Reed: Acta Metall. 49 (2001) 4113-4125.

18) J. X. Yang, Q. Zheng, X. F. Sun, H. R. Guan and Z. Q. Hu: Mater. Sci. Eng. A 67 (2007) 100-108.
19) S. Tin and T. M. Pollock: Mater. Sci. Eng. A 348 (2003) 111-121.

20) A. C. Yeh and S. Tin: Metall. Trans. A 37A (2006) 2621-2631.

21) C. T. Sims, N. S. Stoloff and W. C. Hagel: Superalloys II, (John Wiley \& Sons, New York, 1987) pp. 221-226.

22) A. Volek, R. F. Singer, R. Buergel, J. Grossmann and Y. Wang: Metall. Trans. A 37A (2006) 405-410.

23) L. Liu, T. Huang, Y. Xiong, A. Yang, Z. Zhao, R. Zhang and J. Li: Proc. 10th Int. Symp. on Superalloys, ed. by K. A. Green, T. M. Pollock, H. Harada, T. E. Howson, R. C. Reed, J. J. Schirra and S. Walston, (TMS, Warrendale, PA, 2004) pp. 493-500.

24) J. G. Snow: Allied-Signal Aerospace Company, Garrett Engine Division, (1988) CAGE 9AA11.

25) C. T. Sims, N. S. Stoloff and W. C. Hagel: Superalloys II, (John Wiley \& Sons, New York, 1987) pp. 62-66.

26) C. T. Sims, N. S. Stoloff and W. C. Hagel: Superalloys II, (John Wiley \& Sons, New York, 1987) p. 78.

27) J. S. Hou and J. T. Guo: J. Mater. Eng. Perform. 15 (2006) 67-75.

28) Q. Z. Chen, C. N. Jones and D. M. Knowles: Mater. Sci. Eng. A 385 (2004) 402-418.

29) C. T. Sims, N. S. Stoloff and W. C. Hagel: Superalloys II, (John Wiley \& Sons, New York, 1987) pp. 39-40.

30) C. T. Sims, N. S. Stoloff and W. C. Hagel: Superalloys II, (John Wiley \& Sons, New York, 1987) pp. 255-261. 